\title{
Job Stress, Social Anxiety and Social Skills in Male and Female I.T. Executives
}

\author{
Urvashi Singh $^{1}$, Shalini Singh ${ }^{2}$, Poonam ${ }^{3}$
}

\section{ABSTRACT}

The present study was conducted to investigate the gender difference in job stress, social anxiety and social skills between male and female IT executives. A total sample of 200 I.T. executives (100 males and 100 females) was taken from the private I.T. companies of Gurgaon and Faridabad. Job Stress Survey (Spielberger and Vagg, 1999), Social Skills Scale (Albert, 2005) and Social Anxiety Scale (Liebowitz, 2004) were administered to measure these variables. Data was analyzed by using t-test. Results clearly revealed the significant gender differences in the above measures. Job stress and social anxiety were found high in males while females had better social skills than male IT executives.

Keywords: Job Stress, Social Anxiety, Social Skills, I.T. Executives

Stress is an important psychological concept that can affect health, well being and job performance in negative dimensions (Mojoyinola, 1984; Olayey, 2002). According to Arnold (1995), stress is a word derived from latin word 'Stingere' which means to draw tight. It is considered as a force that pushes a physical or psychological factor beyond its range of stability, producing a strain within the individual. The experience of stress can alter the person's emotional state, the way they think and behave and can also produce changes in their physiological function (Haider, 2008). Lazarus (1966) conceived stress to be a threat of anticipation of future harm, either physical or psychological events that lower an individual selfesteem. It is an affective behaviour and physical response to aversive stimuli in the environment. According to Selye (1976), stress is the non-specific response of the body to the demand made upon it. It puts excessive demands that disturb the physiological, sociological and psychological equilibrium of an individual.

\footnotetext{
${ }^{1}$ Asstt. Professor, Draunacharya College, Gurgaon, India

${ }^{2}$ Professor, Deptt. of Psychology, M.D. University, Rohtak, India

${ }^{3}$ Research Scholar, Deptt. of Psychology, M.D. University, Rohtak, India

*Responding Author

Received: February 3, 2017; Revision Received: March 26, 2017; Accepted: March 29, 2017

(C) 2017 Singh U, Singh S, Poonam; licensee IJIP. This is an Open Access Research distributed under the terms of the Creative Commons Attribution License (www.creativecommons.org/licenses/by/2.0), which permits unrestricted use, distribution, and reproduction in any Medium, provided the original work is properly cited.
} 
Stress may be acute or chronic in nature (Akinboye and Adeymo, 2002). It occurs in different forms, i.e., may be psychological, emotional, social or occupational. Job related stress experienced by workers at work is called job stress. There are number of factors, i.e., poor working conditions, excessive work load, shift work, long hours of work, role ambiguity, role conflict, shifting hours, role conflict, poor relations with boss, colleagues or subordinates, risk and danger in work set up etc. that lead to stress.

Certain responses indicate the presence of job stress in an individual or group. It may manifest various symptoms like insomnia, headache, lack of concentration, low morale, high social anxiety, and lack of social skills. Job stress can overwhelm and grows as well to employees who are continually trying to meet their job deadlines (Albert, 2001). This tension to meet competitive demands of society and work deadlines lead to social anxiety. Social anxiety is the fear of interaction with other people that brings on self-consciousness, feelings of being negatively judged and evaluated that sometimes leads to avoidance. This feeling of inadequacy, inferiority, embarrassment sometimes lead to poor social skills. Allen \& Madeline (2002) asserted that people who suffer from social anxiety or shyness are not ignorant of social cues but feel embarrassment in social interactions and communication skills. Though there have been research studies that talk about the relationship between stress, social anxiety and social skills (Alex, 2005; Elena, 2006, Angelico, 2013) but the research evidence in relation to these variables pertaining to gender differences is very scarce. Since in current world of information technology

both males and females are meeting deadlines of their targets and are under lot of job stress, the need of an hour is to investigate the gender differences in job stress, social anxiety and social skills in IT employees.

\section{Problem}

To explore the gender differences in job stress, social anxiety and social skills in male and female IT executives.

\section{Hypothesis}

There would be significant gender differences in job stress, social anxiety and social skills in male and female IT executives.

\section{METHODOLOGY}

\section{Design}

Two group research designs were used to find out gender differences in job stress, social anxiety and social skills among IT executives.

\section{Sample}

The sample of 100 male and 100 female IT executives was selected from IT companies of Faridabad and Gurgaon. The age range was from 27 to 32 years with work experience of 2-3 years.

(C) The International Journal of Indian Psychology, ISSN 2348-5396 (e)| ISSN: 2349-3429 (p) | 136 


\section{Tools}

1. Job Stress Survey (Spielberger and Vagg, 1999) : It assesses the perceived frequency and severity of occurrence of 30 stressful work related events faced by employees in various situations. This job stress survey consists of three scale and six subscales. Job Stress Index Scale provides an estimate of the overall level of occupational stress.

2. Social Skills Scale (Albert, 2005): It consists of 18 multiple choice items and each item followed by three choices. It measures various components of social skills such as, communication skills, body language, social insight, behaviour and comfort.

3. Social Anxiety Scale (Liebowitz, 2004): It has 16 multiple choice items and each followed by three choices. It assesses the way that social anxiety plays a role in life across a variety of situations.

\section{Procedure}

All the respondents were approached individually. The confidentiality of information was assured. All the questionnaires were administered as per the instructions and after that every scale was scored as per manual. Then the entire data was analyzed by using t-test.

\section{RESULTS AND DISCUSSION}

Table 1:Mean Difference between Male and Female IT Executives across the Variables under Study

\begin{tabular}{|l|l|l|l|l|}
\hline Variables & Gender & M & SD & t-value \\
\hline \multirow{2}{*}{ Job Stress } & M & 36.3 & 6.6 & \multirow{2}{*}{$8.6^{* *}$} \\
\hline \multirow{2}{*}{ Social Anxiety } & F & 28.4 & 4.4 & \multirow{2}{*}{$4.8^{*}$} \\
& F & 28.7 & 5.6 & \multirow{2}{*}{$6.2^{*}$} \\
\hline \multirow{2}{*}{ Social Skills } & M & 24.2 & 4.4 & 7.0 \\
& F & 42.4 & 6.7 & \\
\hline
\end{tabular}

$* * \mathrm{p}<0.01, * \mathrm{p}<0.05$

The objective of the present study was to investigate the gender differences in job stress, social anxiety and social skills in male and female IT executives. As perusal of results in Table No. 1 clearly revealed that there was significant gender difference in job stress social anxiety and social skills among IT executives. Males reported higher job stress $(\bar{X}=28.7, \sigma=6.2)$ than females which further led to significantly low social skills to cope up with stress. On the other hand, females had higher social skills (i.e. $\bar{X}=46.7, \sigma=9.2$ ) in terms of adequate body language, social insight to overcome strenuous task, effective communication skill and good comfort between work set-up and personal life. Wong (2008) reported the gender differences in perceived personal stress. Delva (2002) reported doctors having high workload and leading to high social anxiety. Alex (2004) reported positive relationship between social anxiety and high stress as reported by males IT executives in the present sample. It is so because when the individual is 
under work stress, doesn't interact with society much, and remains quite isolated in social situations leading to anxiety and lack social skills. This low level of social skills makes their incapable to cope up with work situations and to be balanced in life.

\section{CONCLUSION}

The present study in today's corporate world suggests that females despite of having multiple responsibilities at home and work set up as well remain less stressed have low social anxiety and better social skills. The need of an hour is to conduct some workshops by management where they train employees by some life skill training modules for experiencing moderate stress, less anxiety and high social skills.

\section{Acknowledgments}

The author appreciates all those who participated in the study and helped to facilitate the research process.

Conflict of Interests: The author declared no conflict of interests.

\section{REFERENCES}

Akinboye, J.O.; Akinboye, D.A. and Adeyemo, D.O. (2002). Coping with stress in life and workplace. Ibadan: Stirling-Hordon Pub.

Alex, A.K. (2004). Psychology of Social Skills. NJ: Albert Publications.

Alex, L.E. (2005). The Basic of Social Anxiety. London: Book Press.

Allen, T. and Madeline, H. (2002). The Gale Encyclopedia of Mental Disorders. American Library Association: Thomson Gale Publishers.

Angelico, A.P. (2013). Social Anxiety Disorder and Social Skills: A Critical Review of Literature. International Journal of Behavioural Consultation and Therapy, 7(4), 215223.

Arnold, J., Cooper, C.L. and Robertson, C.T. (1995). Work Psychology: Understanding Human Behaviour in the Work Place. London: Pitman Pub.

Delva, M.D., Kirby, J.R., Khapper, C.K. (2002). Postal Survey of approach as to learning among Ontario physicians: Implications for continuing Medical Education. Brit Med Journal, 325, 1218-1220.

Elena, L.A. (2005). Psychology of our lives. New York: Education Association Press.

Haider, Y. (2008). Organizational role stress : Confirmatory factor analysis approach. Asia Pacific Business Review, 1, 1-13.

Lazarus, R.S. (1966). Psychological Stress and the Coping Process. New York: McGraw Hill.

Mojoyinola, J.K. (1984). Occupational Stress Among the Student Nurses of University College Hospitals (U.C.H.). Ibadan. Its Effects on their Mental Health and Well-being. Unpub. B.Sc. Project, University of Ibadan. 


\section{Job Stress, Social Anxiety and Social Skills in Male and Female I.T. Executives}

Olaleye, B.A. (2002). Psycho-social Effects of Job Stress and Burnout Syndrome Among Nurses in State owned Hospitals in Oyo State. M.S.W. Project (Unpub.) University of Ibadani Nigeria.

Selye, H. (1976). The Stress of Life. New York: McGraw Hill.

Wong JGWS (2001). Doctors and Stress. Medical Bulletin, 13, 210-11.

How to cite this article: Singh U, Singh S, Poonam (2017), Job Stress, Social Anxiety and Social Skills in Male and Female I.T. Executives, International Journal of Indian Psychology, Volume 4, Issue 2, No. 95, ISSN:2348-5396 (e), ISSN:2349-3429 (p), DIP:18.01.174/20170402, ISBN:978-1-365-84231-3 